\title{
Water treatment sludge can be used as an adsorbent for heavy metals in wastewater streams
}

\author{
Y.-F. Zhou \& R. J. Haynes \\ School of Land, Crop and Food Sciences/CRC CARE, \\ The University of Queensland, Australia
}

\begin{abstract}
Throughout the world, alum is the most widely used coagulant in drinking water treatment. The waste stream from water treatment is alum-derived water treatment sludge and in most localities large quantities of this material are deposited in waste disposal areas. Reuse of this waste stream in an environmentally sustainable manner is therefore a priority. Research has shown that the material is an effective adsorbent of phosphate from aqueous solutions, but its use as an adsorbent for heavy metals has not been investigated. Our research showed that water treatment sludge was an effective adsorbent for $\mathrm{Pb}(\mathrm{II}), \mathrm{Cr}(\mathrm{III})$ and $\mathrm{Cr}(\mathrm{VI})$. Adsorption isotherm data fitted equally well to Freundlich and Langmuir equations and kinetic data correlated well to a pseudosecond-order kinetic model, suggesting that the mechanism involved was chemisorption. Adsorption was $\mathrm{pH}$-dependant with percentage sorption of $\mathrm{Pb}$ (II) and $\mathrm{Cr}(\mathrm{III})$ increasing greatly with increasing $\mathrm{pH}$ and that of $\mathrm{Cr}(\mathrm{VI})$ decreasing. $\mathrm{Cr}(\mathrm{VI})$ could be removed from sludge surfaces with $0.1 \mathrm{M} \mathrm{NaOH}$. At a concentration of $0.1 \mathrm{M}, \mathrm{HNO}_{3}$ was effective at removing adsorbed $\mathrm{Cr}$ (III) and $\mathrm{Pb}$ (II) from the sludge surfaces and regeneration was successful for eight sorption/removal cycles. Other work showed that water treatment sludge had adsorbent properties for $\mathrm{Cu}, \mathrm{Zn}, \mathrm{Cd}, \mathrm{As}$ and $\mathrm{Se}$. It was concluded that water treatment sludge is a suitable material from which to develop a low-cost adsorbent for removal of both heavy metal cations and anions from wastewater streams.
\end{abstract}

Keywords: water treatment sludge, adsorption isotherms, $\mathrm{Cr}(\mathrm{III}), \mathrm{Cr}(\mathrm{VI}), \mathrm{Pb}(\mathrm{II})$. 


\section{Introduction}

Unlike organic contaminants, most heavy metals in the environment do not undergo microbial or chemical degradation and therefore total amounts accumulated and their ecotoxicological effects persist for long periods after their introduction. Treatment processes for metal-contaminated wastewater include chemical precipitation, membrane filtration, ion exchange, coagulation/precipitation and adsorption. Adsorption is a process by which the heavy metal contaminants are removed from aqueous solution through sorption onto the surface of a material. Activated carbon has been the conventionally adopted adsorbent, but its use is limited by its high cost and difficulties with regeneration [1]. As a result, there is growing research interest in the use of waste products from industry as inexpensive adsorbents [2].

Alum-derived water treatment sludge is a material deposited in waste disposal areas in many parts of the world [3]. Indeed, alum is the most widely used coagulant in drinking water treatment [4]. Once the alum dissolves, $\mathrm{Al}^{3+}$ exists in solution as aluminiumhexahydronium ion $(\mathrm{A} 1.6 \mathrm{H} 2 \mathrm{O})^{3+}$. These ions can sequentially dissociate as $\mathrm{pH}$ increases, leaving $\mathrm{OH}$ in place of $\mathrm{OH}_{2}$ to form species such as $\left[\mathrm{Al}\left(\mathrm{H}_{2} \mathrm{O}\right)_{5} \mathrm{OH}\right]^{2+}$ and $\left[\mathrm{Al}(\mathrm{H} 2 \mathrm{O})_{4}(\mathrm{OH})_{2}\right]^{+}$. These positively charged species polymerize to form positively charged polynuclear complexes, which form a gel-like substance that adsorbs and coagulates colloidal materials such as soluble organic matter and fine soil particles. During flocculation, sedimentation and filtration, colloids in the raw water remain entrapped in, or adsorbed to, the Al gel and after dewatering the water treatment sludge is transferred to disposal sites. Beneficial use of this material would reduce both the cost and need for disposal. Research has shown that water treatment sludge can be used as an effective adsorbent for phosphate [3], but little research has centred on its use as a heavy metal adsorbent.

The purpose of this study was to investigate the possibility of removing $\mathrm{Cr}(\mathrm{II}), \mathrm{Cr}(\mathrm{VI})$ and $\mathrm{Pb}(\mathrm{II})$ from aqueous solutions using alum-derived water treatment sludge.

\section{Materials and methods}

Water treatment sludge was collected from Seqwater Mount Crosby water treatment plant (Brisbane). Specific surface area of samples was determined by the BET/ $\mathrm{N}_{2}$-adsorption method and zero point of charge was determined using a Laser Zeta meter. Elemental composition of materials was measured by ICPAES after digestion in a microwave system with $\mathrm{HNO}_{3}, \mathrm{HCl}$ and $\mathrm{HF}$. The sludges were subjected to X-ray diffraction (XRD) analysis to determine their mineralogy. Cation exchange capacity of materials was determined at $\mathrm{pH} 7.0$ using $1 \mathrm{M}$ ammonium acetate and $\mathrm{pH}$ and electrical conductivity (EC) were measured in a 1:5 material:water ratio [5] using a $\mathrm{pH} /$ conductivity meter (Horiba F-54 BW).

Batch adsorption studies were performed to determine the extent of adsorption of each individual heavy metal ion at room temperature $\left(25^{\circ} \mathrm{C}\right)$. All 
experiments were carried out in triplicate at a constant ionic strength provided by $0.01 \mathrm{M} \mathrm{NaNO}_{3}$. Metal solutions, with the desired metal concentration, were prepared in $0.01 \mathrm{M} \mathrm{NaNO}_{3}$ using $\mathrm{Pb}\left(\mathrm{NO}_{3}\right)_{2}, \mathrm{Cr}\left(\mathrm{NO}_{3}\right)_{3}$ and $\mathrm{Na}_{2} \mathrm{CrO}_{4}$. A measured amount of sludge was weighed into $50 \mathrm{~mL}$ centrifuge tubes and $10 \mathrm{~mL}$ of $0.01 \mathrm{M}$ $\mathrm{NaNO}_{3}$ was added. The mixture was shaken for $1 \mathrm{~h}$ and then adjusted to desired $\mathrm{pH}$ using $\mathrm{HNO}_{3}$ or $\mathrm{NaOH}$. Once the $\mathrm{pH}$ had stabilized, $10 \mathrm{~mL}$ of an individual heavy metal solution (at twice the desired final metal concentration) was added and the $\mathrm{pH}$ was adjusted again. The mixture was shaken on an end-over-end shaker for $2 \mathrm{~h}$. During adsorption, the $\mathrm{pH}$ was checked and readjusted, if necessary, every half-hour. The resulting solution was centrifuged (4,000 rpm for $10 \mathrm{~min}$.), filtered and the supernatant was analysed for the appropriate aqueous heavy metal by ICP-AES. The percentage of metal adsorbed was calculated from the difference between that added and that remaining in solution.

The effect of $\mathrm{pH}$ on adsorption was investigated over the $\mathrm{pH}$ range of 2 to 9 with an initial metal concentration of $1 \mathrm{mM}$ and adsorbent dosage of $10 \mathrm{~g} \mathrm{~L}^{-1}$. Sorption was found to be highly $\mathrm{pH}$-dependant and at $\mathrm{pH} 5.0$, adsorption amounted to approximately $60 \%$ of that added for all three ions. As a result, $\mathrm{pH}$ 5 was chosen to study the effects of initial metal concentration, contact time, temperature and adsorbent dose on metal removal.

Eight different initial concentrations of $\mathrm{Cr}$ (III), $\mathrm{Cr}$ (VI) and $\mathrm{Pb}$ (II) ranging from $0.4 \mathrm{mM}$ to $8 \mathrm{mM}$ were used (at an adsorbent dosage level of $10 \mathrm{~g} \mathrm{~L}^{-1}$ ) to measure the effect of initial metal concentration on adsorption. Adsorption data (equilibrium metal concentration versus quantity adsorbed) were fitted to the Langmuir and Freundlich equations. The effect of contact time, varying from 15 min to $360 \mathrm{~min}$., was studied at a dosage level of $10 \mathrm{~g} \mathrm{~L}^{-1}$ and an initial concentration of $1 \mathrm{mM}$. The data was fitted to pseudo-first-order and pseudosecond-order kinetic models. The effect of adsorbent dose $(2.5,5,7.5,10,12.5$, $15,17.5$ and $20 \mathrm{~g} \mathrm{~L}^{-1}$ ) was studied at an initial concentration of $1 \mathrm{mM}$ (contact time $=120 \mathrm{~min}$.) and the effect of temperature was determined at 20, 30, 40, 50 and $60^{\circ} \mathrm{C}$ (adsorbent dose $=10 \mathrm{~g} \mathrm{~L}^{-1}$ ).

\section{Results and discussion}

\subsection{Properties of the material}

As expected, the main metallic element present in water treatment sludge was $\mathrm{Al}$ (122 $\left.\mathrm{g} \mathrm{kg}^{-1}\right)$ and some Fe $\left(24 \mathrm{~g} \mathrm{~kg}^{-1}\right)$ was also present. The material had an organic $\mathrm{C}$ content of $103 \mathrm{~g} \mathrm{~kg}^{-1}$. X-ray diffraction analysis revealed the sludge consisted of poorly crystalline amorphous material and small amounts of gehlenite $\left(\mathrm{Ca}_{2} \mathrm{Al}_{2} \mathrm{SiO}_{7}\right)$ were also present. Adsorption of inorganic and organic anionic species to the hydroxyl-Al polymers during coagulation probably inhibits crystallization to $\mathrm{Al}(\mathrm{OH})_{3}$ [6] and as shown here, the water treatment sludge exists as a relatively stable amorphous material with a high surface area.

The surface area of the material $\left(97.3 \mathrm{~m}^{2} \mathrm{~g}^{-1}\right)$ is similar to that recorded by Lee et al. [7] of 61-67 $\mathrm{m}^{2} \mathrm{~g}^{-1}$ for water treatment sludge but much greater than that reported for other waste adsorbents such as coal fly ash $\left(2-8 \mathrm{~m}^{2} \mathrm{~g}^{-1}\right)$ [8] or 
382 Waste Management and the Environment V

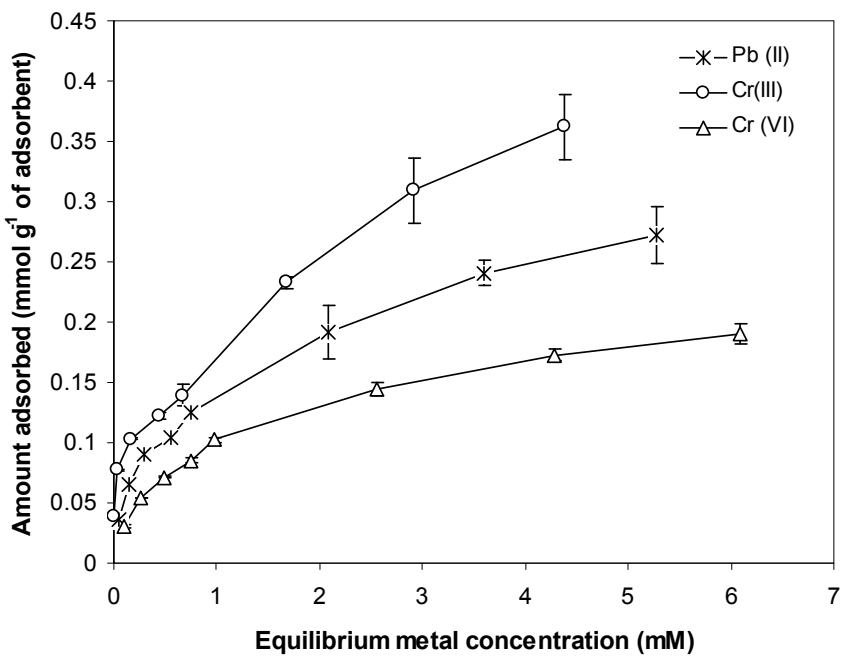

Figure 1: Effect of initial metal concentration on the quantity of $\mathrm{Pb}(\mathrm{II})$, $\mathrm{Cr}(\mathrm{III})$ and $\mathrm{Cr}(\mathrm{VI})$ adsorbed by water treatment sludge.

Table 1: Isotherm constants and correlation coefficients $\left(\mathrm{R}^{2}\right)$ for the adsorption of $\mathrm{Pb}(\mathrm{II}), \mathrm{Cr}(\mathrm{III})$ and $\mathrm{Cr}(\mathrm{VI})$ onto water treatment sludge.

\begin{tabular}{|c|c|c|c|c|c|c|}
\hline \multirow[t]{2}{*}{ Metal } & \multicolumn{3}{|c|}{ Langmuir isotherm } & \multicolumn{3}{|c|}{ Freundlich isotherm } \\
\hline & $\begin{array}{c}q_{\max } \\
\left(\mathrm{mmol} \mathrm{g}^{-1}\right)\end{array}$ & $\begin{array}{c}b \\
\left(L^{\prime} m_{m o l}{ }^{-1}\right)\end{array}$ & $R^{2}$ & $K_{f}$ & $1 / n$ & $R^{2}$ \\
\hline $\mathrm{Pb}$ (II) & 0.30 & 1.31 & 0.98 & 0.14 & 0.42 & 0.99 \\
\hline $\mathrm{Cr}$ (III) & 0.37 & 1.67 & 0.92 & 0.19 & 0.32 & 0.94 \\
\hline $\mathrm{Cr}(\mathrm{VI})$ & 0.21 & 1.12 & 0.99 & 0.09 & 0.43 & 0.99 \\
\hline
\end{tabular}

bauxite processing residue mud (red mud) (13-30 $\left.\mathrm{m}^{2} \mathrm{~g}^{-1}\right)$ [9]. The high surface area of water treatment sludge is a positive attribute when it is being used as an adsorbent. The sludge had a $\mathrm{pH}$ of 6.8 , an $\mathrm{EC}$ of $1.21 \mathrm{mS} \mathrm{cm}^{-1}$ and a PZC of 6.7.

\subsection{Effect of initial metal concentration}

Adsorption of $\mathrm{Pb}(\mathrm{II}), \mathrm{Cr}(\mathrm{III})$ and $\mathrm{Cr}(\mathrm{VI})$ increased with increasing equilibrium concentration of the metal ion and reached a maximum value as the adsorbent became progressively saturated (Fig. 2). Data fitted equally well to either the Freundlich or Langmuir models [10] with correlation coefficients close to unity (Table 1). The Freundlich equation explains adsorption onto a heterogeneous surface with uniform energy. The linear form of the model is expressed as:

$$
\log q_{e}=\log K_{f}+\frac{1}{n} \log C_{e}
$$




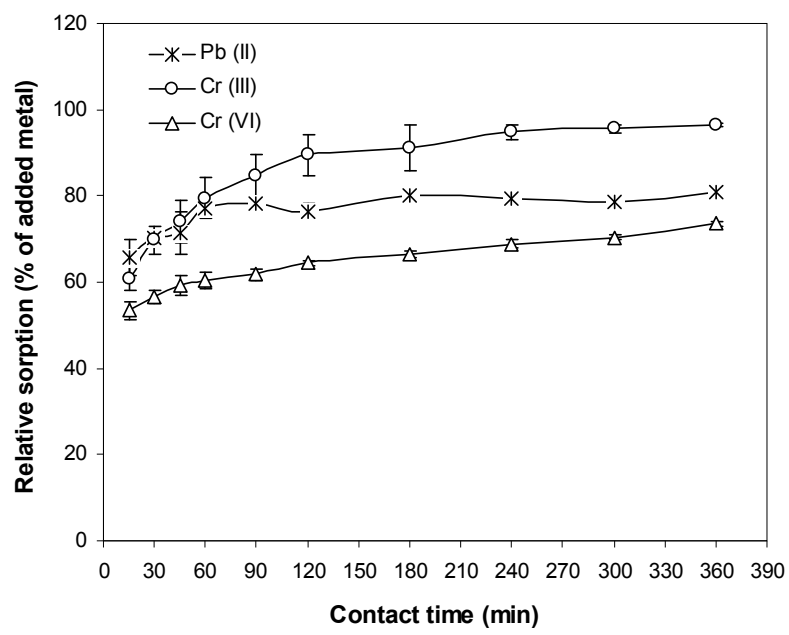

Figure 2: $\quad$ Effect of contact time on the quantity of $\mathrm{Pb}(\mathrm{II}), \mathrm{Cr}(\mathrm{III})$ and $\mathrm{Cr}(\mathrm{VI})$ adsorbed by water treatment sludge.

where $q_{e}$ and $C_{e}$ are the equilibrium concentrations of metal in the adsorbed $\left(\mathrm{mmol} \mathrm{g} \mathrm{g}^{-1}\right)$ and liquid phases $\left(\mathrm{mmol} \mathrm{L}^{-1}\right)$ respectively. $K f$ and $n$ are the Freundlich constants which are related to adsorption capacity and intensity, respectively. On the other hand, the Langmuir equation is based on monolayer adsorption on active sites of the adsorbent. The linear form is expressed as:

$$
\frac{C_{e}}{q_{e}}=\frac{C_{e}}{Q_{m}}+\frac{1}{Q_{m} b}
$$

where $q_{e}$ and $C_{e}$ are equilibrium concentrations of metal in the adsorbed (mmol $\left.\mathrm{g}^{-1}\right)$ and liquid phases (mmol L $\mathrm{L}^{-1}$ ) respectively. $\mathrm{Q} m$ and $b$ are the Langmuir constants which are related to the adsorption capacity and energy of adsorption, respectively.

For the Freundlich model, the slope $1 / n$ is the sorptive intensity and values between 0.1 and 1.0, as recorded here, indicate beneficial sorption [11]. The maximum sorption capacity $\left(\mathrm{q}_{\max }\right)$ obtained by the Langmuir model was highest for $\mathrm{Cr}(\mathrm{III})$ and showed the order: $\mathrm{Cr}(\mathrm{III})>\mathrm{Pb}$ (II) $>\mathrm{Cr}(\mathrm{VI})$ (Table 1). A similar trend was apparent for the Langmuir intensity factor $b$ and the Freundlich $K_{f}$ factor. This supports results of research with other adsorbents which has generally shown that at equimolar concentrations, $\mathrm{Cr}(\mathrm{III})$ is preferentially adsorbed compared to $\mathrm{Cr}(\mathrm{VI})$ and that sorption of $\mathrm{Cr}(\mathrm{III})$ exceeds that of $\mathrm{Pb}$ (II) $[12,13]$. 


\subsection{Effect contact time}

The effects of contact time on the adsorption of $\mathrm{Pb}$ (II), $\mathrm{Cr}$ (III) and $\mathrm{Cr}$ (VI) are shown in Fig. 2. The adsorption process was rapid and at a contact time of 120 min., $90 \%$ or greater of maximum sorption had occurred. Thus, for batch studies, a period of $120 \mathrm{~min}$. is adequate for adsorption of these ions onto sludge surfaces. In order to evaluate the kinetic mechanisms that control the adsorption process, pseudo-first-order and pseudo-second-order models were employed to interpret the experimental data. The pseudo-first order equation can be represented by:

$$
\log \left(q_{e}-q_{t}\right)=\log q_{e}-\frac{k_{1}}{2.303} t
$$

where $k_{1}\left(\mathrm{~min}^{-1}\right)$ is the pseudo-first-order adsorption rate constant, $q_{t}$ is the amount adsorbed at time $t(\mathrm{~min})$ and $q_{e}$ denotes the amount adsorbed at equilibrium, both in mmol $\mathrm{g}^{-1}$. The pseudo-second-order equation can be expressed as:

$$
\frac{t}{q_{t}}=\frac{1}{k_{2} q_{e}{ }^{2}}+\frac{1}{q_{e}} t
$$

where $k_{2}\left[\mathrm{~g}(\mathrm{mmol} \mathrm{min})^{-1}\right]$ is the adsorption rate constant of pseudo-second-order.

Based on the obtained correlation coefficients, the pseudo-second order equation gave a better fit to the experimental kinetic data than the pseudo-first order model and calculated pseudo-second order $q_{e}$ values were in good agreement with the experimental values (data not presented). This suggests that chemisorption rather than diffusion/ion exchange was the rate-limiting step to sorption [14]. Such a finding is not surprising since chemisorption of metal cations, as well as anions such as phosphate, onto the surface of amorphous hydroxyl-Al is a well-recognised phenomenon $[6,15]$. Chemisorption includes both specific adsorption and surface precipitation with precipitates forming beyond a certain level of metal sorption [16].

In addition, there will be some metal adsorption onto surfaces of organic matter which was coagulated with the hydroxyl-Al. Adsorption to organic matter occurs through formation of coordination complexes and chelates with surface functional groups (e.g. carboxylic, phenol, enolic, alcoholic $\mathrm{OH}$ and $\mathrm{C}=\mathrm{O}$ ) [17].

\subsection{Effect of $\mathrm{pH}$}

Adsorption edges for $\mathrm{Cr}^{3+}$ and $\mathrm{Pb}^{2+}$ showed increasing sorption from near zero to near complete over a relatively small $\mathrm{pH}$ range (Fig. 3). This is because the variable charge on hydroxyl-Al surfaces arises from protonation and deprotonation of the potential determining $\mathrm{M}-\mathrm{OH}_{2}{ }^{0.5+}$ and $\mathrm{M}-\mathrm{OH}^{0.5-}$ groups. The surface becomes increasingly negatively charged as hydroxyl ion activity (and $\mathrm{pH}$ ) increase, thus favouring specific adsorption of cations. In addition, as $\mathrm{pH}$ is 


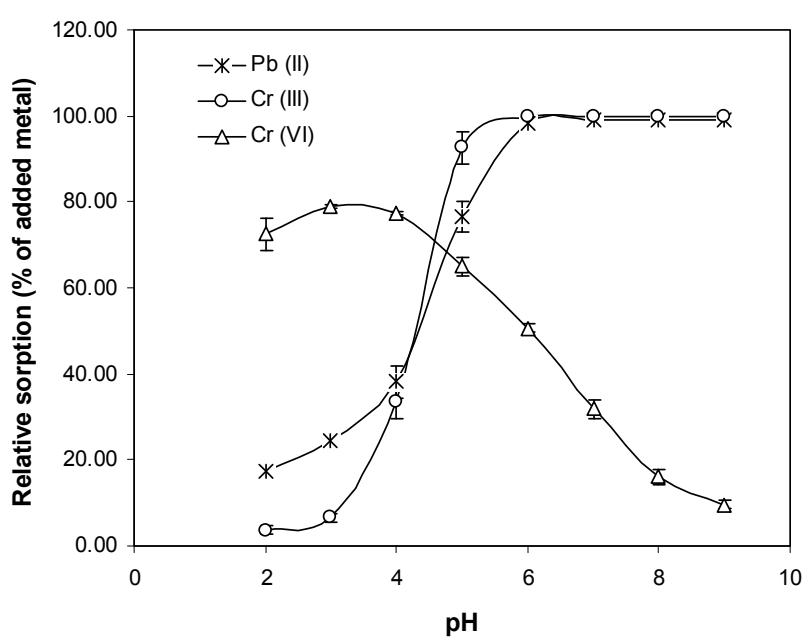

Figure 3: $\quad$ Effect of $\mathrm{pH}$ on the quantity of $\mathrm{Pb}(\mathrm{II}), \mathrm{Cr}(\mathrm{III})$ and $\mathrm{Cr}(\mathrm{VI})$ adsorbed by water treatment sludge.

raised, hydrolysis of hydrated cations proceeds and their adsorption generally occurs preferentially as hydrolysed ions (i.e. $\mathrm{PbOH}^{+}$rather than $\mathrm{Pb}^{2+}$ ). $\mathrm{As}$ adsorption sites become saturated, ultimately precipitation of metal hydroxides/oxides at the surfaces occurs. As a result, adsorption edges reach $100 \%$ sorption.

By contrast, the increasingly negative surface charge conferred by increasing $\mathrm{pH}$, hinders anion adsorption and, as a result, $\mathrm{Cr}(\mathrm{VI})$ sorption showed a maximum between $\mathrm{pH} 3$ and 4 and declined thereafter with increasing $\mathrm{pH}$ (Fig. 1). Hexavalent $\mathrm{Cr}$ may exist in the aqueous phase in a number of anionic forms with hydrogen chromate $\left(\mathrm{HCrO}_{4}^{-}\right)$predominating in dilute solutions between $\mathrm{pH}$ 1-6, chromate $\left(\mathrm{CrO}_{4}{ }^{2-}\right)$ above $\mathrm{pH} 6.4$ and dichromate $\left(\mathrm{Cr}_{2} \mathrm{O}_{7}{ }^{2-}\right)$ below $\mathrm{pH} 3$ in concentrated solutions $(>1.0 \mathrm{mM})$ [18]. The predominant form of $\mathrm{Cr}(\mathrm{VI})$ adsorbed to sludge surfaces under our experimental conditions is likely to have been $\mathrm{HCrO}_{4}^{-}$.

At intermediate $\mathrm{pH}$ values of between 4.5 and 6.0, the sludge samples were equally effective for $\mathrm{Cr}(\mathrm{III}) / \mathrm{Pb}$ (II) or $\mathrm{Cr}(\mathrm{VI})$ sorption (Fig. 1). Thus, this $\mathrm{pH}$ range would be desirable where $\mathrm{Cr}(\mathrm{III})$ and $\mathrm{Cr}(\mathrm{VI})$ or $\mathrm{Pb}(\mathrm{II})$ and $\mathrm{Cr}(\mathrm{VI})$ were present together in contaminated wastewater and water treatment sludge was being used as an adsorbent.

\subsection{Effect of temperature}

Results showed that percentage adsorption of $\mathrm{Cr}(\mathrm{III}), \mathrm{Pb}(\mathrm{II})$ and $\mathrm{Cr}(\mathrm{VI})$ all tended to increase with increasing temperature between 20 and $50^{\circ} \mathrm{C}$ suggesting that their sorption onto sludge surfaces is an endothermic process (data not shown). From a practical viewpoint, the small temperature-induced changes 
observed suggest that sludge can be used successfully as an adsorbent between 20 and $50^{\circ} \mathrm{C}$.

\subsection{Effect of adsorbent dose}

The effects of adsorbent dose on percentage sorption of $\mathrm{Cr}(\mathrm{III}), \mathrm{Pb}(\mathrm{II})$ and $\mathrm{Cr}(\mathrm{VI})$ are shown in Fig. 4. As expected, percentage sorption increased with increasing dose and tended to reach a saturation level at high doses. This is attributable to the surface area and number of adsorption sites being increased with increasing dose. The effect was more pronounced for $\mathrm{Pb}(\mathrm{II})$ and $\mathrm{Cr}(\mathrm{VI})$ than for the more strongly sorbed $\mathrm{Cr}(\mathrm{III})$.

\subsection{Desorption/regeneration}

The ease and extent of desorption of metals from adsorbent surfaces is important since once the material becomes saturated with contaminant metals, and is no longer effective, it needs to be regenerated and reused. When desorption was carried out in the $0.01 \mathrm{M} \mathrm{NaOH}$ electrolyte, very small quantities of metal ions were desorbed (data not presented). For this reason acid and sometimes alkaline solutions are commonly used for regeneration [19].

The metal cations $\mathrm{Pb}$ (II) and $\mathrm{Cr}$ (III) were effectively desorbed with $\mathrm{HNO}_{3}$ (at 0.1 and $0.5 \mathrm{~N}$ concentrations) and the anionic $\mathrm{Cr}(\mathrm{VI})$ by $\mathrm{NaOH}$ (at $0.01,0.1$ and $0.5 \mathrm{~N}$ concentrations) (data not presented). The vast majority of metal was removed in the first desorption cycle. Such results reflect the fact that an acidic environment is least favourable for $\mathrm{Pb}$ (II) and $\mathrm{Cr}$ (III) adsorption (and favours desorption) whilst an alkali one is least favourable for $\mathrm{Cr}(\mathrm{VI})$ adsorption (Fig. 3).

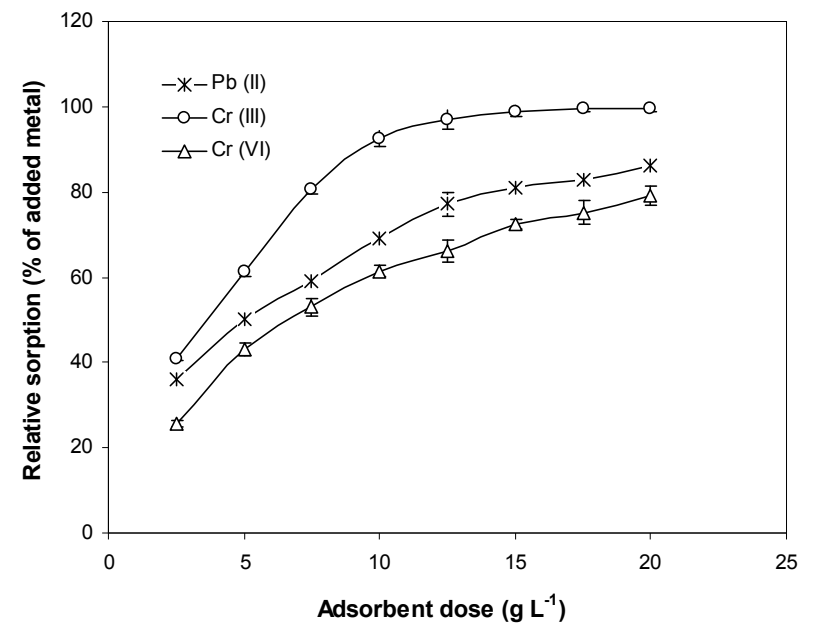

Figure 4: Effect of adsorbent dose on the quantity of $\mathrm{Pb}$ (II), $\mathrm{Cr}$ (III) and $\mathrm{Cr}(\mathrm{VI})$ adsorbed by water treatment sludge. 


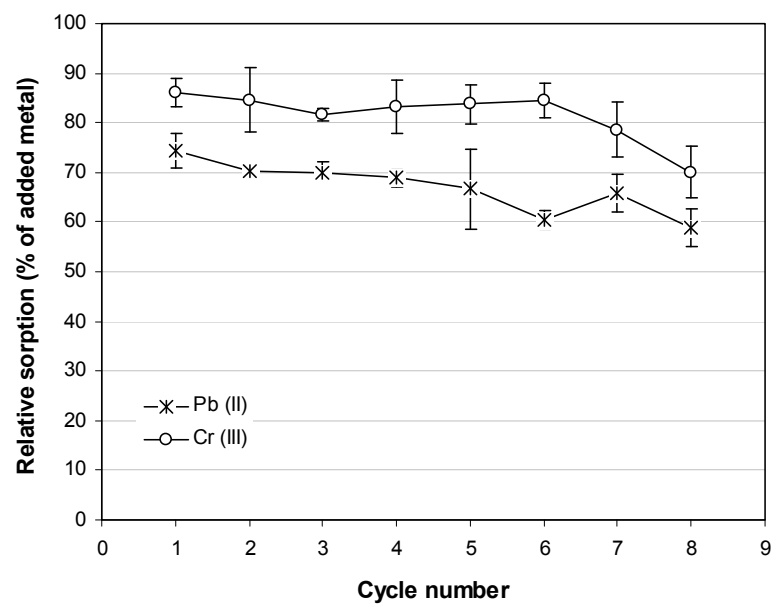

Figure 5: Relative sorption of $\mathrm{Pb}(\mathrm{II})$ and $\mathrm{Cr}(\mathrm{III})$ over eight successive adsorption/regeneration cycles using $0.1 \quad \mathrm{~N} \quad \mathrm{HNO}_{3}$ as the regenerating agent.

As shown in Fig. 5, subjecting the two samples of water treatment sludge to eight successive cycles of sorption/regeneration using $0.1 \mathrm{~N} \mathrm{HNO}_{3}$ resulted in only a very small loss in adsorption efficiency for $\mathrm{Pb}$ (II) and $\mathrm{Cr}$ (III). This suggests that a water treatment sludge-based metal cation adsorption system would be able to function over many operational cycles without deleterious effects to its sorption capabilities.

\section{Conclusions}

The present study reveals that spent alum-derived water treatment sludge, a material which is often disposed of in landfills, can be employed as an effective adsorbent for sorption of $\mathrm{Cr}(\mathrm{III}), \mathrm{Pb}(\mathrm{II})$ and $\mathrm{Cr}(\mathrm{VI})$ from aqueous solutions. Adsorption capacity is strongly dependent on initial metal ions concentration, initial $\mathrm{pH}$ and dosage, experimental data can be fitted well to Freundlich and Langmuir equations, kinetic data is strongly correlated to a pseudo-second-order kinetic model and for $\mathrm{Cr}$ (III) and $\mathrm{Pb}$ (II) the adsorbent surfaces can be regenerated using $0.1 \mathrm{M} \mathrm{HNO}_{3}$. Water treatment sludge is suitable material for development of a low-cost adsorbent for removal of $\mathrm{Cr}$ and $\mathrm{Pb}$ from wastewater streams.

\section{Acknowledgements}

We thank Robert Townsley of Seqwater (Mt Crosby) for supplying the water treatment sludge. We are indebted to Mark Raven of CSIRO Land and Water for mineralogical analysis of the materials, Dr Xin-Lin Hong of Wuhan University 
College of Chemistry and Molecular Sciences for surface area determinations, and David Appleton of the University of Queensland for metal determinations.

\section{References}

[1] Gupta, V. K. \& Ali, I., Adsorbents for water treatment: low-cost alternatives to carbon. Encyclopedia of Surface and Colloid Science, Vol. 2, ed. A.T. Hubbard, Marcel Dekker, New York, pp. 136-166, 2002

[2] Babel, S. \& Kurniawan, T. A., 2003. Low-cost adsorbents for heavy metals uptake from contaminated water: a review. Journal of Hazardous Materials B97, pp. 219-243, 2003.

[3] Babatunde, A.O. \& Zhao, Y.O., Constructive approaches toward water treatment works sludge management: an international review of beneficial reuses. Critical Reviews in Environmental Science and Technology 37, pp. 129-164, 2007.

[4] Faust, D., \& Aly, O.M., Chemistry of Water Treatment. CRC Press, Boca Raton, 1998.

[5] Rayment, G.E. \& Higginson, F.R., Australian Handbook of Soil and Water Chemical Methods. Inkata Press, Melbourne, 1992

[6] Haynes, R.J. \& Swift, R.S., Adsorption of phosphate by aluminium-organic matter complexes as affected by $\mathrm{pH}$ and drying. Journal of Soil Science, 40, pp. 773-781, 1989.

[7] Lee, C.E., Yang, W.F. \& Chiou, S.S., Utilization of water clarifier sludge for copper removal in a liquid fluidized-bed reactor. Journal of Hazardous Materials B129, pp. 58-63, 2006.

[8] Wang, S.B., Soudi, M., Li, L. \& Zhu, Z.H., Coal ash conversion into effective adsorbents for removal of heavy metals and dyes from wastewater. Journal of Hazardous Materials B133, pp. 243-251, 2006.

[9] Paramguru, R.K., Rath, P.C. \& Misra, V.N., Trends in red mud utilization a review. Mineral Processing and Extractive Metallurgy Review 26, pp. 129, 2005.

[10] Apak, R., Adsorption of heavy metal ions on soil surfaces and similar substances. Encyclopedia of Surface and Colloid Science, Vol. 2, ed A.T. Hubbard, Marcel Dekker, New York, pp. 385-417, 2002.

[11] Treybal, R.E. Mass Transfer Operations, third edition. McGraw-Hill, New York, 1980.

[12] Gupta, V.K., Gupta, M. \& Sharma, S., Process development for the removal of lead and chromium from aqueous solutions using red mud-an aluminium industry waste. Water Research 35, pp. 1125-1134, 2001.

[13] Bradl, H.B., Adsorption of heavy metal ions on soils and soils constituents. Journal of Colloid and Interface Science 277, pp. 1-18, 2004.

[14] Ho, Y.S. \& McKay, G., Pseudo-second order model for sorption processes. Process Biochemistry 34, pp. 451-465, 1999.

[15] Saka, U.K., Taniguchi, S. \& Sakurai, K. Adsorption behaviour of cadmium, zinc, and lead on hydroxyaluminium- and hydroxyaluminosilicate- 
montmorillonite complexes. Soil Science Society of America Journal 65, pp. 694-703, 2002.

[16] McBride, M.B., Chemisorption and precipitation reactions. Handbook of Soil Science, ed. M.E. Sumner, CRC Press, Boca Raton, 2000, pp. B265302.

[17] Stevenson, F.J., Humus Chemistry. Genesis, Composition, Reactions. John Wiley, New York, 1994.

[18] James, B.R., Chromium. Encyclopedia of Water Science, ed. B.A. Stewart \& T.A. Howell, Marcel Dekker, New York, 2003, pp. 75-79.

[19] Zhou, Y-F. \& Haynes, R.J., Sorption of heavy metals by inorganic and organic components of solid wastes: significance to use of wastes as low cost adsorbents and immobilizing agents. Critical Reviews in Environmental Science and Technology (in press), 2010. 